\title{
Classificar motivos de consulta e procedimentos com a ICPC na prática clínica?
}

Daniel Pinto*

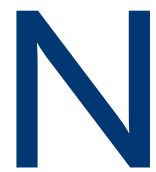

o último número da Revista Portuguesa de Medicina Geral e Familiar (RPMGF), Raquel Braga fez-nos reflectir sobre a utilização da Classificação Internacional de Cuidados Primários (entre nós conhecida pela sua abreviatura em inglês - ICPC) nos registos de saúde electrónicos. ${ }^{1}$ Parece existir uma tendência para que as rubricas da ICPC substituam o texto livre nas notas de seguimento (vulgarmente conhecidas por registos SOAP). Esta tendência pode ser observada em registos clínicos reais, comunicações de casos clínicos em congressos e manuscritos submetidos à RPMGF. Seria importante, por um lado, perceber se este caminho será o mais útil para melhorar a qualidade dos registos clínicos e, por outro, estudar a dimensão real deste fenómeno e porque alguns médicos optam por proceder assim. Neste texto, debruçar-me-ei sobre a primeira questão.

Alguns utilizadores da classificação parecem confundir a estrutura das notas de seguimento no método de Weed, ${ }^{2}$ divididas em subjectivo, objectivo, avaliação e plano, com a capacidade da ICPC para classificar motivos de consulta, problemas de saúde e procedimentos. ${ }^{3}$ Isto é de particular relevância quando tentam utilizar um conjunto de rubricas da ICPC como registo do campo “subjectivo". Quando o fazem, geralmente ignoram dois factos: que nem tudo o que deve ser registado no campo subjectivo constitui um motivo de consulta classificável através da ICPC e que a classificação dos motivos de consulta obedece a regras que não são cumpridas na generalidade das consultas. A ICPC define três princípios na classificação do motivo de consulta: a identificação do motivo deve ser feita de forma explícita e acordada entre o médico e o doente (sempre que necessário, o médico deverá clarificar o motivo de consulta); a rubrica da ICPC a utilizar deverá ser tão próxima quanto possível das palavras do doente; e o motivo de consulta é re-

*Editor da Revista Portuguesa de Medicina Geral e Familiar Observador no Comité Internacional de Classificações da Associação Mundial de Médicos de Família (WONCA) gistado a partir do ponto de vista do doente, não sendo aplicadas as regras de classificação dos problemas. ${ }^{3}$ Ao definir estes princípios, a ICPC associa a definição do motivo de consulta ao método clínico centrado no paciente, nomeadamente à exploração de sentimentos, ideias e expectativas acerca da doença. ${ }^{4}$ Os motivos de consulta espelham a agenda do doente. No entanto, em grande parte das consultas, os médicos saltam os passos necessários à identificação e clarificação do motivo de consulta e não exploram em profundidade suficiente as razões que levaram o doente a procurá-los, o que inviabiliza uma classificação adequada à luz dos princípios da ICPC. Presumir a intenção do doente e colocar a agenda do médico como motivo de consulta é algo contrário ao espírito da ICPC.

Dizer que a classificação dos motivos de consulta obriga a pôr em prática o método clínico centrado no paciente e os princípios definidos na ICPC não significa que o motivo de consulta tenha de ser classificado de forma sistemática em todas as consultas. A classificação do motivo de consulta deve ter um propósito. É útil em contexto de investigação, por exemplo, quando se pretende conhecer o que leva uma população a procurar cuidados de saúde ${ }^{5}$ ou o valor preditivo de um sintoma para um determinado diagnóstico; ${ }^{6}$ ou em contexto de treino na utilização da ICPC. Já não é claro qual o propósito que deva levar ao seu uso generalizado na prática clínica diária, em que o tempo disponível limita a capacidade de quem classifica para cumprir os princípios da classificação e do método clínico centrado no paciente.

Uma classificação é útil para analisar um grande número de registos, abstraindo informação acerca das características que são comuns a um determinado grupo, mas com isso descartando informação pormenorizada acerca da variabilidade individual. Assim, a classificação dos motivos de consulta não pode substituir o registo de informação detalhada acerca dos sintomas, sentimentos e expectativas de cada doente, sob pena de se perderem a tonalidade e a ri- 
queza da descrição individual e o registo clínico se tornar uma mancha cinzenta em que todos os doentes são iguais. Na perspectiva do doente individual, a classificação do motivo de consulta terá sempre de ser feita em conjunto com o registo clínico em texto livre e não em sua substituição. Na perspectiva do grupo, ao contrário do que sucede para os problemas de saúde, não estão implementados sistemas que permitam agregar a informação de vários registos, o que impossibilita a análise em larga escala dos motivos de consulta. Ainda que isso fosse possível, desconhece-se de que forma a análise dos motivos de consulta poderia ser utilizada para além do contexto de investigação, nomeadamente para planeamento e gestão dos serviços de saúde, como acontece com os problemas.

A classificação de procedimentos com a ICPC é teoricamente mais simples, uma vez que depende exclusivamente do médico e não obriga a explorar a agenda do doente. Contudo, um estudo de 2010 verificou que o maior número de erros de classificação num grupo de internos de medicina geral e familiar portugueses acontecia precisamente nos procedimentos. ${ }^{7}$ Isto acontece provavelmente devido à existência de um número limitado de rubricas, com pouca granularidade, o que suscita aos utilizadores muitas dúvidas no momento de classificar.

Por parte de quem financia o sistema de saúde, a classificação dos procedimentos permite, em conjunto com os problemas de saúde, avaliar aquilo que o médico faz na consulta. Nos sistemas em que os médicos recebem um pagamento por acto (fee for service), a classificação dos procedimentos é geralmente um passo necessário para a cobrança ao Estado ou à companhia de seguros. Mas os financiadores também podem utilizar os procedimentos para auditar a qualidade dos cuidados prestados, definindo um conjunto de actividades, e consequentemente códigos, que têm de estar presentes em determinadas circunstâncias. Auditar informaticamente grandes volumes de registos médicos procurando pela existência de determinados códigos de procedimentos é algo de muito tentador face à alternativa que constitui a análise manual do texto livre por auditores humanos. Contudo, na avaliação da qualidade, a utilização de medidas facilmente auditáveis não se traduz necessariamente em melhores cuidados prestados aos doentes. ${ }^{8}$

Recentemente, a Administração Central do Sistema de Saúde definiu como indicador de qualidade das unidades de saúde familiar na área da educação e promoção da saúde o registo de uma rubrica “-45 no P do SOAP” nas con- sultas de grupos vulneráveis e de risco. ${ }^{9}$ Apesar de facilmente auditável, tal como nos motivos de consulta, a utilização de códigos para classificar os procedimentos não deve substituir o registo individual em texto livre e não se vislumbra qual o benefício que traz ao doente. No caso concreto das intervenções para promoção da saúde, é importante detalhar os temas abordados, o que foi proposto e o plano acordado com o doente. Se a intervenção for mais estruturada, envolvendo, por exemplo, técnicas de entrevista motivacional, então a classificação mais apropriada para o procedimento será provavelmente um código -58 (aconselhamento terapêutico/escuta terapêutica) e não -45 (observação/educação para a saúde/aconselhamento / dieta).

Em conclusão, da forma como parece estar a ser feita, a classificação de motivos de consulta e procedimentos de forma sistemática na prática clínica diária não contribui para melhorar os registos clínicos, pelo contrário: provavelmente contém muitos erros, quando usada em substituição do texto livre faz com que se perca informação acerca do indivíduo e não permite abstrair informação de um grande número de consultas por falta das ferramentas apropriadas.

\section{REFERÊNCIAS BIBLIOGRÁFICAS}

1. Braga R. Os registos clínicos e a codificação. Rev Port Med Geral Fam 2012 MarAbr; 28 (2): 155-6.

2. Weed LL. Medical records that guide and teach. N Engl J Med. 1968 Mar 21; 278 (12): 652-7.

3. Comissão de Classificações da Organização Mundial de Ordens Nacionais, Academias e Associações Académicas de Clínicos Gerais/Médicos de Família (WONCA). Classificação Internacional de Cuidados de Saúde Primários. $2^{\mathrm{a}}$ edição - revista. Lisboa: Administração Central do Sistema de Saúde, IP \& Associação Portuguesa de Médicos de Clínica Geral; 2011.

4. Levenstein JH, McCracken EC, McWhinney IR, Stewart MA, Brown JB. The patient-centred clinical method. 1. A model for the doctor-patient interaction in family medicine. Fam Pract 1986 Mar; 3 (1): 24-30.

5. Rodrigues JG. Porque consultam os utentes o seu Médico de Família? Rev Port Clin Geral 2000 Nov-Dez; 16 (4): 442-52.

6. Soler JK, Okkes I, Oskam S, van Boven K, Zivotic P, Jevtic M, et al.;Transition Project. An international comparative family medicine study of the Transition Project data from the Netherlands, Malta, Japan and Serbia. An analysis of diagnostic odds ratios aggregated across age bands, years of observation and individual practices. Fam Pract 2012 Jun; 29 (3): 315-31.

7. Pinto D, Corte-Real S. Codificação com a Classificação Internacional de Cuidados Primários (ICPC) por internos de Medicina Geral e Familiar. Rev Port Clin Geral 2010 Jul-Ago; 26 (4): 370-82.

8. Pogach L, Aron DC. Sudden acceleration of diabetes quality measures. JAMA 2011 Feb 16; 305 (7): 709-10.

9. Guia para aplicação do diagnóstico do desenvolvimento organizacional nas USF - DIOR-USF. Administração Central do Sistema de Saúde. Lisboa, Abril 2012. Disponivel em: http://www.acss.min-saude.pt/Portals/0/Guia\%20DiOrUSF.pdf [acedido a 01/09/2012].

\section{ENDEREÇO PARA CORRESPONDÊNCIA}

danielpinto@rpmgf.pt 